\title{
Impact of supervision of methadone consumption on deaths related to methadone overdose (1993-2008): analyses using OD4 index in England and Scotland
}

\author{
John Strang, professor of the addictions, ${ }^{1}$ Wayne Hall, NHMRC Australia fellow and professor of public health \\ policy, ${ }^{2}$ Matt Hickman, reader in public health and epidemiology, ${ }^{3}$ Sheila M Bird, senior scientist, ${ }^{4}$ visiting \\ professor $^{5}$
}

1King's College London, National Addiction Centre, Institute of Psychiatry, London SE5 8BB, UK

${ }^{2}$ School of Population Health, University of Queensland, Australia

${ }^{3}$ Social Medicine, University of Bristol, Bristol, UK

${ }^{4}$ MRC Biostatistics Unit, Cambridge, UK

${ }^{5}$ Department of Mathematics and Statistics, Strathclyde University, Strathclyde, UK

Correspondence to: J Strang

john.strang@kcl.ac.uk

Cite this as: $B M J$ 2010;341:C4851 doi:10.1136/bmi.c4851

\section{ABSTRACT}

Objective To evaluate the impact of introduction of supervision of methadone dosing on deaths related to overdose of methadone in Scotland and England between 1993 and 2008 while controlling for increased prescribing of methadone.

Design Analysis of annual trends in deaths related to overdose of methadone in relation to defined daily doses of methadone prescribed.

Setting Scotland and England.

Population Deaths in which methadone was coded as the only drug involved or as one of the drugs implicated.

Main outcome measure Annual OD4-methadone index (number of deaths with methadone implicated per million defined daily doses of methadone prescribed in that year).

Results OD4-methadone declined substantially over the four epochs of four years between 1993 and 2008. It decreased significantly $(\mathrm{P}<0.05)$ in 10 of 12 epoch changes: in Scotland from 19.3 (95\% confidence interval 15 to 24 ) to 4.1 (2.8 to 5.4 ) and finally to 3.0 (2.4 to 3.5 ) for methadone only deaths (and from 58 to 29 to 14 for deaths with any mention of methadone); in England from 27.1 (25 to 29) to 24.8 (23 to 27 ) and finally to 5.8 (5.3 to 6.3) for methadone only deaths (and from 46 to 42 to 12 for deaths with any mention of methadone). The decreases in OD4-methadone were closely related to the introduction of supervised dosing of methadone in both countries, first in Scotland (1995-2000) and later in England (1999-2005). These declines occurred over periods of substantial increases in prescribing of methadone (18-fold increase in defined daily doses per million population annually in Scotland and sevenfold increase in England).

Conclusions Introduction of supervised methadone dosing was followed by substantial declines in deaths related to overdose of methadone in both Scotland and England. OD4-methadone index analyses, controlled for substantial increases in methadone prescribing in both countries, identified at least a fourfold reduction in deaths due to methadone related overdose per defined daily dose (OD4-methadone) over this period.

\section{INTRODUCTION}

Heroin and other opiates contribute disproportionately to deaths from drug overdoses, compared with their low prevalence of use in many developed countries. ${ }^{1-3}$ Deaths due to overdose of opiates, for example, accounted for 9\% of deaths in young Australian adults under the age of 50 in 1998 and for more than $10 \%$ in several European cities despite the fact that they were used by less than $1 \%$ of adults in any year. ${ }^{45}$ We need to understand better the factors driving these deaths if they are to be reduced. Opioids are implicated in more than three quarters of all illicit drug related deaths in the United Kingdom. ${ }^{2-7}$

The prescribed opioid methadone is used as maintenance treatment for opioid dependence, leading to a major reduction in deaths from overdose. ${ }^{8-14}$ Almost all methadone is prescribed for treatment of opioid addiction; for example, $99.5 \%$ of all methadone prescriptions in Scotland in 2008-9 were for "treatment of substance dependence." ${ }^{6}$ The vast majority of this is prescribed as oral liquid/linctus: $100 \%$ in Scotland and $96 \%$ in England. ${ }^{615}$

Careless or unsanctioned use of methadone contributes to deaths due to overdose. ${ }^{2}$ During the 1990s, for example, methadone was implicated in as many drug related deaths in the UK as was heroin. ${ }^{16}{ }^{17}$ Recommendations were made for UK clinical practice to align with other countries, with the introduction of new arrangements for supervised consumption of methadone, ${ }^{1819}$ and major change occurred over the past decade. ${ }^{15}$

Methadone prescribing practice in the UK was changed in the mid-late 1990s, with the aim of reducing deaths related to overdose of methadone; daily dispensing and supervision of methadone dosing were introduced or increased to reduce diversion. ${ }^{21819}$ These changes occurred first in Scotland, from 1992 onwards, ${ }^{20-29}$ and only later in England (fig 1). ${ }^{30-37}$

We examined the impact of these changes on deaths related to overdose of methadone per million defined daily doses (see later for definition) of prescribed methadone: the OD4-methadone index. We 

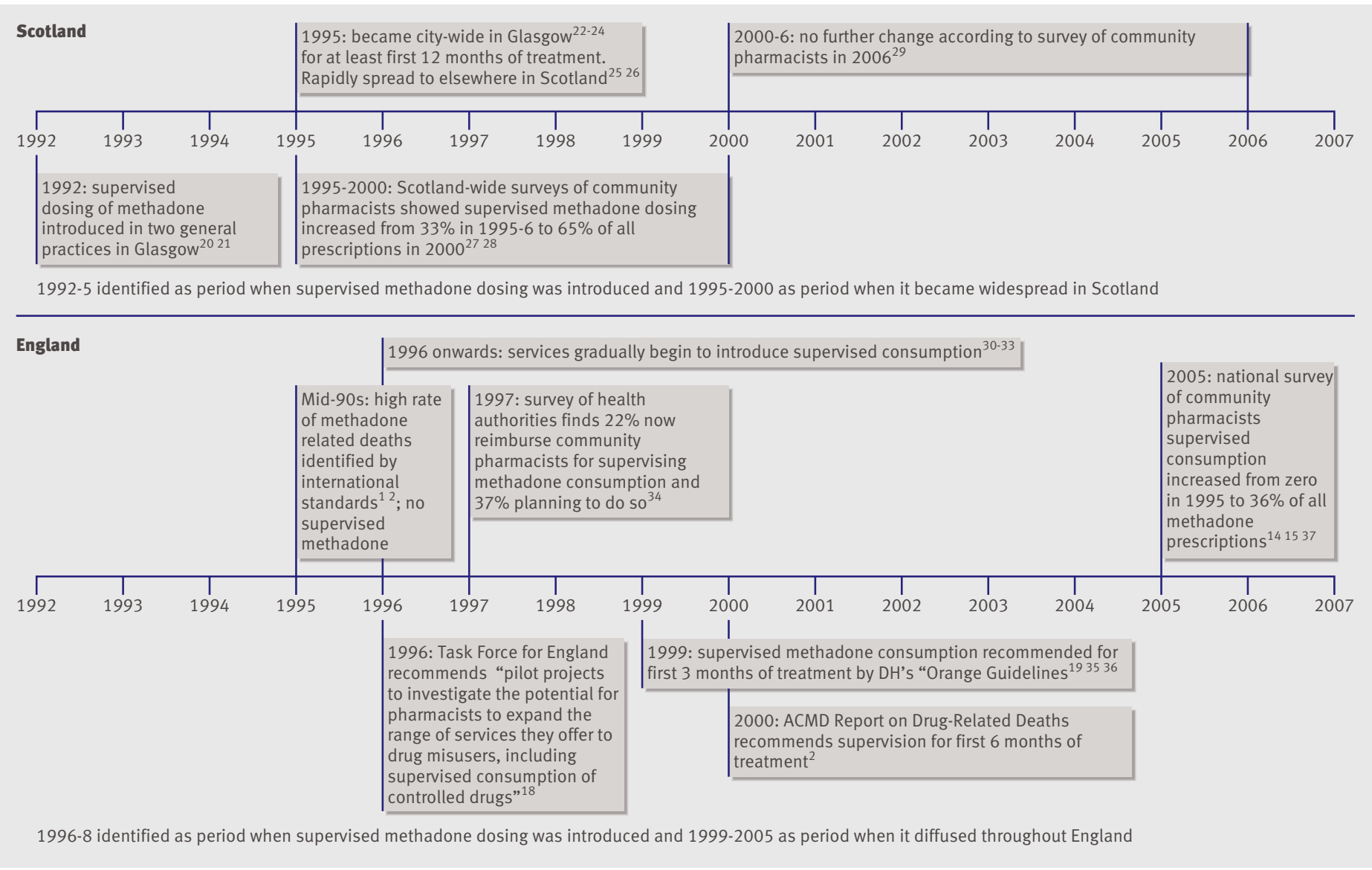

Fig 1| Timelines of introduction and spread of supervision of methadone consumption in Scotland and England

examined whether reductions in OD4-methadone index (both narrowly and broadly defined) coincided with the period of introduction of supervision of methadone dosing in Scotland and England.

\section{METHODS}

We defined the annual OD4-methadone index as the number of deaths with methadone implicated per million defined daily doses of methadone prescribed in that year. The OD4-methadone index enabled us to examine methadone's contribution to deaths due to opioid overdose while controlling for expansion of methadone treatment during the study period. We defined methadone related deaths in two ways: deaths due to overdose in which methadone was the only drug present and deaths due to overdose in which methadone was one of two or more drugs that were present. These calculations therefore produce two versions of the OD4-methadone index: the OD4-methadone (sole drug) index and the OD4-methadone (any mention) index.

\section{Statistical methods}

We examined annual changes within each country (that is, separately for England and Scotland). We additionally examined the data as four epochs of four years each and did statistical analysis. In deriving 95\% confidence intervals for the OD4-methadone index, we assumed that the number of deaths due to methadone overdose per calendar year and per four year epoch followed a Poisson distribution.

\section{OD4-methadone index}

Deaths related to overdose of methadone

We obtained mortality data for Scotland and England (special retrieval for England only, on request, from the Office for National Statistics). ${ }^{67}$ We obtained data on the numbers of drug related deaths in which methadone was the "only drug" reported in coroners' reports and the number in which it was "one of more than one drug" reported by coroners. ${ }^{6}$ Coronial processes differ in practice and definitions between Scotland and England, so we examined changes over time within each country.

\section{Defined daily dose of prescribed methadone}

We obtained national data separately, by special request, on the total quantity of methadone prescribed annually by the NHS in Scotland and in England (General Register Office Scotland and Department of Health NHS Statistics) for 1993-2008 (tables 1 and 2). We arranged for retrieval of these NHS prescription data for all instances in which the reported indication was "treatment of substance dependence."

We used the World Health Organization's definition of defined daily dose as "the assumed average 
Table 1| Methadone data—Scotland (population 5.2 million in 2008)

\begin{tabular}{|c|c|c|c|c|c|c|c|c|c|c|c|c|c|c|c|c|}
\hline & 1993 & 1994 & 1995 & 1996 & 1997 & 1998 & 1999 & 2000 & 2001 & 2002 & 2003 & 2004 & 2005 & 2006 & 2007 & 2008 \\
\hline \multicolumn{17}{|l|}{ Deaths } \\
\hline Methadone only & 10 & 21 & 21 & 27 & 20 & 8 & 5 & 5 & 8 & 14 & 12 & 9 & 20 & 35 & 29 & 14 \\
\hline Any mention of methadone & 25 & 55 & 58 & 99 & 87 & 64 & 62 & 56 & 71 & 99 & 87 & 80 & 72 & 97 & 114 & 181 \\
\hline \multicolumn{17}{|l|}{ Quantity prescribed } \\
\hline Methadone kg (mg × 1 million) & 31.0 & 51.7 & 72.1 & 90.8 & 112.3 & 127.7 & 145.5 & 173.6 & 210.0 & 255.0 & 308.1 & 363.2 & 421.9 & 473.1 & 520.6 & 572.5 \\
\hline Year on year increase (\%) & - & 66.7 & 39.6 & 25.9 & 23.6 & 13.8 & 13.9 & 19.3 & 21.0 & 21.4 & 20.8 & 17.9 & 16.2 & 12.2 & 10.0 & 10.0 \\
\hline \multicolumn{17}{|l|}{ Defined daily dose (DDD) calculations } \\
\hline $\begin{array}{l}\text { Methadone DDDs-60 mg daily doses } \\
\text { (millions) }\end{array}$ & 0.52 & 0.86 & 1.20 & 1.51 & 1.87 & 2.13 & 2.43 & 2.89 & 3.50 & 4.25 & 5.13 & 6.05 & 7.03 & 7.89 & 8.68 & 9.54 \\
\hline \multicolumn{17}{|l|}{ OD4 calculations } \\
\hline OD4 score (methadone only) (per million) & 19.4 & 24.4 & 17.5 & 17.8 & 10.7 & 3.8 & 2.1 & 1.7 & 2.3 & 3.3 & 2.3 & 1.5 & 2.8 & 4.4 & 3.3 & 1.5 \\
\hline $\begin{array}{l}\text { OD4 score (any mention of methadone) } \\
\text { (per million) }\end{array}$ & 48.4 & 63.9 & 48.2 & 65.4 & 46.5 & 30.1 & 25.6 & 19.4 & 20.3 & 23.3 & 16.9 & 13.2 & 10.2 & 12.3 & 13.1 & 19.0 \\
\hline
\end{tabular}

maintenance dose per day for a drug used for its main indication in adults." 38 This provided an estimate of consumption in a fixed unit of measurement that is independent of price and formulation and so enabled assessment of trends in methadone use. We used a methadone daily dose of $60 \mathrm{mg}$ as the defined daily dose because this was the lower point of the recommended dose range and was close to the average dose prescribed in the UK over the period of study-namely, 47.3 (SD 28.2) $\mathrm{mg}$ in 1995 and $56.3(28.7) \mathrm{mg}$ in 2005. ${ }^{15} 193739$

\section{Calculation of the OD4-methadone index}

To examine the temporal relation between methadone prescribing and the number of methadone related deaths, we calculated the OD4-methadone index separately for Scotland and England in respect of deaths in which methadone was the sole drug mentioned (OD4methadone (sole drug)) and deaths in which there was any mention of methadone (OD4-methadone (any mention)).

\section{Timing of policy initiative}

Supervision of methadone consumption was introduced in Scotland in two general practices in Glasgow in 1992 and subsequently across Glasgow, and then widely throughout Scotland during 1995-2000 (fig 1, top). In England, no supervised consumption existed at the time of a national survey of pharmacists in 1995; it began to appear in 1996 and spread more slowly across England throughout 1999-2005 (fig 1, bottom).

\section{RESULTS}

Over the 16 year period 1993-2008, 1307 deaths related to overdose of methadone occurred in Scotland and 4317 in England. Methadone was the sole reported drug in $258(20 \%)$ of these deaths in Scotland and in 2343 (54\%) in England.

\section{Methadone prescribing}

Over the 16 year study period, 65 million defined daily doses of methadone were prescribed in Scotland (table 1) and 198 million in England (table 2). Rates of prescribing increased dramatically over the study period (1993-2008) in both countries. In Scotland, it increased from fewer than 0.1 million defined daily doses per million population in the early 1990 s to 1.8 million by 2008 (table 1). In England, methadone prescribing increased from approximately 0.1 million defined daily doses per million population in 1993 to just over 0.5 million by 2008 (table 2).

\section{Deaths related to overdose of methadone}

In Scotland (table 1), deaths related to overdose of methadone peaked in 1996 and 1997 (and in 1996 for methadone as sole drug); they then declined for the next four years and remained at this lower level for several years. Methadone only deaths began to increase again in the mid-2000s.

In England (table 2), deaths related to overdose of methadone peaked in 1997 and 1998 (and in 1997 for methadone as sole drug) and then declined for six years after 1998. They began to increase again before the final four year epoch (table 3) but had not regained their 1997 level by 2008.

\section{OD4-methadone index calculations}

The OD4-methadone index for both deaths due to overdose with methadone only and those in which methadone was mentioned declined substantially in both Scotland and England.

In Scotland, the OD4-methadone (sole drug) index declined after 1996; annual deaths due to overdose decreased from around 20 per million defined daily doses to only two by 1999. From 2000 onwards, this OD4 index remained below five (table 1 and fig 2, top). Thus, over a four year period (1997-2000), the deaths with methadone reported as sole drug reduced from 20 to three per million defined daily doses and remained around this lower level thereafter. The reduction in deaths with any mention of methadone was more gradual, from 58 deaths per million defined daily doses in the first four year epoch to 29 in the second and thereafter to 18 and 14 (tables 1 and 3; fig 2, top).

In England, the OD4-methadone (sole drug) index was at a high level until 1998; annual deaths due to overdose in which only methadone was reported 
Table 2 | Methadone data-England (population 51.4 million in 2008)

\begin{tabular}{|c|c|c|c|c|c|c|c|c|c|c|c|c|c|c|c|c|}
\hline & 1993 & 1994 & 1995 & 1996 & 1997 & 1998 & 1999 & 2000 & 2001 & 2002 & 2003 & 2004 & 2005 & 2006 & 2007 & 2008 \\
\hline \multicolumn{17}{|l|}{ Deaths } \\
\hline Methadone only & 113 & 144 & 169 & 179 & 268 & 218 & 171 & 144 & 121 & 86 & 71 & 104 & 94 & 121 & 153 & 187 \\
\hline Any mention of methadone & 195 & 254 & 286 & 300 & 402 & 377 & 323 & 257 & 229 & 191 & 189 & 216 & 209 & 229 & 305 & 355 \\
\hline \multicolumn{17}{|l|}{ Quantity prescribed } \\
\hline Methadone $\mathrm{kg}$ (mg $\times 1$ million) & 262.6 & 305.9 & 360.2 & 413.2 & 460.7 & 472.9 & 490.1 & 517.8 & 557.7 & 633.6 & 772.2 & 931.1 & 1127.5 & 1343.0 & 1530.2 & 1730.0 \\
\hline Year on year increase (\%) & - & 16.5 & 17.7 & 14.7 & 11.5 & 2.6 & 3.6 & 5.7 & 7.7 & 13.6 & 21.9 & 20.6 & 21.1 & 19.1 & 13.9 & 13.1 \\
\hline \multicolumn{17}{|c|}{ Defined daily dose (DDD) calculations } \\
\hline $\begin{array}{l}\text { Methadone DDDs—60 mg daily } \\
\text { doses (millions) }\end{array}$ & 4.38 & 5.10 & 6.00 & 6.89 & 7.68 & 7.88 & 8.17 & 8.63 & 9.30 & 10.56 & 12.87 & 15.52 & 18.79 & 22.38 & 25.50 & 28.83 \\
\hline \multicolumn{17}{|l|}{ OD4 calculations } \\
\hline $\begin{array}{l}\text { OD4 score (methadone only) } \\
\text { (per million) }\end{array}$ & 25.8 & 28.2 & 28.2 & 26.0 & 34.9 & 27.7 & 20.9 & 16.7 & 13.0 & 8.1 & 5.5 & 6.7 & 5.0 & 5.4 & 6.0 & 6.5 \\
\hline $\begin{array}{l}\text { OD4 score (any mention of } \\
\text { methadone) (per million) }\end{array}$ & 44.6 & 49.8 & 47.6 & 43.6 & 52.4 & 47.8 & 39.5 & 29.8 & 24.6 & 18.1 & 14.7 & 13.9 & 11.1 & 10.2 & 12.0 & 12.3 \\
\hline
\end{tabular}

ranged from 25 to 35 per million defined daily doses. This OD4 decreased thereafter, and deaths steadily declined over the next six years to around six per million defined daily doses and remained at this lower level (table 2 and fig 2, bottom). A similar reduction in deaths with any mention of methadone occurred; the OD4-methadone (any mention) index decreased from 46 and 42 deaths per million defined daily doses in the first and second four year epochs to 17 and 11 thereafter (tables 2 and 3; fig 2, bottom).

\section{Relation between changes in OD4 and supervised consumption of methadone}

We observed three distinct phases in both of the OD4methadone index scores (methadone only and any mention) in both Scotland and England: an initial steady state, a rapid decline, and then a new steady state. The initial steady state for the OD4-methadone (sole drug) index in Scotland was around 19 in 1993-6 (table 3 and fig 2, top). This was followed by rapid reduction of OD4-methadone down to four during 1997-2000. The reduction tracks the timing of Scotland's adoption of supervised methadone consumption between 1995 and 2000 (fig 1, top).

The initial steady state for the OD4-methadone (sole drug) index in England exceeded 25 (that is, more than 25 deaths per million defined daily doses) until 1998 . This was followed by a decline over a more extended period (1998-2005) to a new lower level of around six deaths per million defined daily doses (tables 2 and 3; fig 2 , bottom). The timing of these changes coincided with the later and more gradual implementation of supervised methadone consumption in England between 1999 and 2005 (fig 1, bottom).

Finally, we examined these data in four epochs of four years each. In Scotland, the largest decline in OD4-methadone occurred between the first and second epochs (table 3). In England, by contrast, the most pronounced decline occurred between the second and third epochs. All changes were statistically significant $(\mathrm{P} \leq 0.02)$ for transitions between epochs for OD4 index involving both methadone only and any mention of methadone, except for the two epoch changes marked with an asterisk in table 3 .

\section{DISCUSSION}

This study shows the value of the OD4-methadone index expressed in terms of defined daily dose in assessing the impact of policy changes on the safety of methadone prescribing. Our findings show a remarkable improvement in the safety of methadone prescribing in both Scotland and England, particularly over the period 1995-2004.

The absence of systematic tracking of deaths has meant that this substantial improvement in the safety of methadone treatment has hitherto been neither detected nor quantified. We found that the timing of these changes was precise and was related to a specific change in clinical practice that occurred at different times in the two countries - namely, the widespread supervision of methadone dosing during the early months of treatment. The previous failure to detect this improved safety may be because the change occurred over a period of very substantial increases in prescribing of methadone.

\section{Other possible explanations}

Before cautiously accepting this inference that the decline in the rate of deaths due to methadone overdose was the result of this increased supervision of dosing, we need to evaluate and exclude other possible explanations of the decline in OD4-methadone. Firstly, we can exclude the possibility that the decline in OD4-methadone reflects either a reduction in availability of heroin, such as occurred in Australia after $2001,{ }^{40}$ or a decline in the number of people using heroin. No evidence exists of any sustained heroin shortage or reduction in the number of heroin users in the UK over the study period. In fact, all indices of the availability and use of heroin, including deaths due to heroin overdose, rose steadily during the study period, ${ }^{41}$ as did the number of heroin dependent people being treated by methadone maintenance. ${ }^{42}$

The same is true for changes in the route of opiate use, such as increased use of non-injecting routes. 
Table $3 \mid$ Changes in OD4 score over four epochs of four years

\begin{tabular}{|c|c|c|c|c|}
\hline Outcome & $1993-6$ & $1997-2000$ & 2001-4 & $2005-8$ \\
\hline \multicolumn{5}{|l|}{ Scotland (population 5.2 million in 2008) } \\
\hline Drug related deaths: methadone as only drug & 79 & 38 & 43 & 98 \\
\hline Drug related deaths: any mention of methadone & 237 & 269 & 337 & 464 \\
\hline Quantity of methadone prescribed ( $\mathrm{mg} \times 1$ million) & 245.6 & 559.1 & 1136.3 & 1988.1 \\
\hline Implied methadone patient years (DDD $(60 \mathrm{mg}) / 365)$ & 11215 & 25530 & 51889 & 90781 \\
\hline OD4 score: methadone only $(95 \% \mathrm{Cl})$ & 19.3 (15 to 24$)$ & $4.1(2.8$ to 5.4$)$ & 2.3 (1.6 to 2.9$) \dagger$ & $3.0(2.4 \text { to } 3.5)^{\star}$ \\
\hline OD4 score: any mention of methadone $(95 \% \mathrm{Cl})$ & $57.9(50$ to 65$)$ & 28.9 (25 to 32$)$ & 17.8 (15.9 to19.7) & $14.0(12.7$ to 15.3$) \ddagger$ \\
\hline \multicolumn{5}{|l|}{ England (population 51.4 million in 2008) } \\
\hline Drug related deaths: methadone as only drug & 605 & 801 & 382 & 555 \\
\hline Drug related deaths: any mention of methadone & 1035 & 1359 & 825 & 1098 \\
\hline Quantity of methadone prescribed ( $\mathrm{mg} \times 1$ million) & 1341.9 & 1941.5 & 2894.6 & 5730.7 \\
\hline Implied methadone patient years (DDD $(60 \mathrm{mg}) / 365)$ & 61274 & 88653 & 132174 & 261676 \\
\hline OD4 score: methadone only $(95 \% \mathrm{Cl})$ & 27.1 (24.9 to 29.2$)$ & $24.8(23.0 \text { to } 26.5)^{\star}$ & 7.9 (7.1 to 8.7$)$ & $5.8(5.3$ to 6.3$)$ \\
\hline OD4 score: any mention of methadone $(95 \% \mathrm{Cl})$ & $46.3(43$ to 49$)$ & $42.0(40$ to 44$) \S$ & 17.1 (15.9 to 18.3$)$ & 11.5 (10.8 to 12.2$)$ \\
\hline \multicolumn{5}{|c|}{$\begin{array}{l}\text { DDD=defined daily dose. } \\
Z \text { scores are provided when } 95 \% \text { confidence intervals overlap. } \\
{ }^{*} \text { All OD } 4 \text { changes across epoch were significant, except for those concluding here. } \\
\dagger Z \text { score versus previous epoch }=2.42 \text {. } \\
\text { †Z score versus previous epoch }=3.25 \text {. } \\
\S Z \text { score versus previous epoch }=2.33 \text {. }\end{array}$} \\
\hline
\end{tabular}

Heroin "chasers" have fewer fatal overdoses than do heroin injectors, ${ }^{43}$ and a considerable proportion of UK heroin users are chasers. ${ }^{445}$ No evidence exists, however, that the proportion of chasers increased over the study period. Even if this had occurred, it would be more likely to reduce deaths due to heroin than deaths involving methadone. It would also not explain the difference in timing between Scotland and England.

Other changes in methadone prescribing and dispensing are unlikely to explain the decline. Recommendations were made to increase doses and rates of daily dispensing of methadone, but doses increased only slowly and the increase in daily dispensing was modest by comparison with the very substantial expansion of supervised methadone consumption in both countries. ${ }^{3746}$

\section{Data sources and collection}

The definition of a death related to overdose of methadone can be restrictive (methadone only) or inclusive (any mention of methadone). Both definitions depend on toxicological assessments and the reporting practices of coroners. We measured deaths in both ways to minimise the impact of these definitions on our findings. The fact that both measures showed parallel changes albeit at different levels over the study period is reassuring. Both also showed the same difference in timing between the two countries. The decline was somewhat faster for methadone only deaths, which one may expect to be more sensitive to any benefits of supervised dosing.

Incompleteness of the data is unlikely to explain the decline. Although dosing data were not available for non-NHS ("private") practice or for methadone dispensing at on-site hospital pharmacies, these practices relate to only small numbers of prescriptions. Only
$1.5 \%$ of all methadone prescriptions were from private practice in 1995 and $1.0 \%$ in $2005,{ }^{1537}$ and on-site dispensing in England was rare, accounting for probably less than $1 \%$ of dispensing.

\section{Conclusions and policy implications}

This is the first study to use publicly available mortality data to assess whether increased supervision of methadone has, as intended, reduced deaths due to overdose involving prescribed methadone. The OD4 index can also potentially be used to assess the safety of other
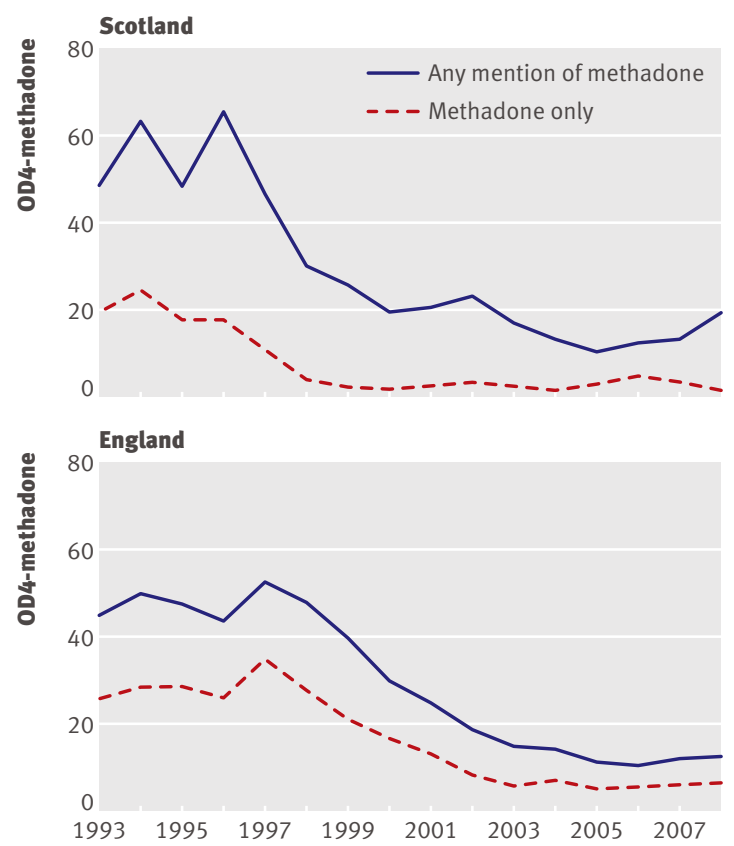

Year

Fig 2 | OD4-methadone index, Scotland and England, 19932008 


\section{WHAT IS ALREADY KNOWN ON THIS TOPIC}

Methadone maintenance treatment has repeatedly been shown, across cultures, settings, and epochs, to reduce mortality substantially among heroin addicts entering treatment

Misuse, unsanctioned co-administration, and poorly compliant intake are all associated with risk of death from overdose of methadone

Risk-benefit analysis shows clear advantages of appropriate provision of methadone maintenance treatment

\section{WHAT THIS STUDY ADDS}

Progressive introduction and use of facilities for supervision of methadone consumption during the 1990 s was associated with a major reduction in death due to methadone overdose

This reduction occurred over a period of continued growth of the heroin addiction problem and also major expansion of methadone provision

The OD4 index (overdose deaths per daily dispensed dose) decreased approximately fourfold in both Scotland and England coinciding with the period of introduction of supervised consumption
7 Office for National Statistics. Deaths related to drug poisoning in England and Wales, 2008. Office for National Statistics, 2009.

8 Mattick RP, Breen C, Kimber J, Davoli M. Methadone maintenance therapy versus no opioid replacement therapy for opioid dependence. Cochrane Database Syst Rev 2009;3:CD002209.

9 National Institute for Health and Clinical Excellence. Methadone and buprenorphine for the management of opioid dependence. NICE, 2007. (Technology appraisal guidance 114.)

10 Bell J, Zador D. A risk-benefit analysis of methadone maintenance treatment. Drug Saf 2000;22:179-90.

11 Kimber J, Copeland L, Hickman M, Macleod J, McKenzie J, De Angelis D, et al. Survival and cessation in injecting drug users: prospective observational study of outcomes and effect of opiate substitution treatment. BMJ 2010;340:C3172.

12 Tober G, Strang J, eds. Methadone matters: evolving community methadone treatment of opiate addiction. Martin Dunitz, 2003.

13 Strain EC, Stitzer ML, eds. The treatment of opioid dependence. Johns Hopkins University Press, 2006.

14 Mattick RP, Ali R, Lintzeris L, eds. Pharmacotherapies for opioid dependence: efficacy cost-effectiveness and implementation guidelines. Informa Healthcare, 2009.

15 Strang J, Sheridan J, Barber N. Prescribing injectable and oral methadone to opiate addicts: results from the 1995 national surve of community pharmacies in England and Wales. $B M$ J 1996;313:270-2.

16 Neeleman J, Farrell M. Suicide and substance misuse. Br J Psychiatry 1997;171:303-4.

17 Hickman M, Madden P, Henry J, Baker A, Wallace C, Wakefield J, et al. Trends in drug overdose deaths in England and Wales 1993-98: methadone does not kill more people than heroin. Addiction 2003;98:419-25.

18 Department of Health. Task force to review services for drug misusers: report of an independent review of drug treatment services in England. Stationery Office, 1996.

19 Department of Health, Scottish Home and Health Department, Welsh Office, Northern Ireland Department of Health and Social Services. Drug misuse and dependence-guidelines on clinical management. Stationery Office, 1999.

20 Wilson P, Watson R, Ralston GE. Methadone maintenance in general practice: patients, workload, and outcomes. BMJ 1994;309:641-4.

21 Scott RTA, Gruer LD, Wilson P, Hinshelwood S. Methadone maintenance treatment-Glasgow has an innovative scheme for encouraging GPs to manage drug misusers. BMJ 1995;310:464-5.

22 Gruer L, Wilson P, Scott R, Elliot L, Macleod J, Harden K, et al. General practitioner centred scheme for treatment of opiate dependent drug injectors in Glasgow. BMJ 1997;314:1730-5.

23 Roberts K, McNulty H, Gruer L, Scott R, Bryson S. The role of Glasgow pharmacists in the management of drug misuse. Int J Drug Policy 1998;9:187-94.

24 Hutchinson SJ, Taylor A, Gruer L, Barr C, Mills C, Elliott L, et al. Oneyear follow-up of opiate injectors treated with oral methadone in a GP-centred programme. Addiction 2000;95:1055-68.

25 Gruer L, Roberts K. New approaches to dispensing controlled drugs: supervised consumption of methadone. In: Sheridan J, Strang J, eds. Drug misuse and community pharmacy. Taylor and Francis, 2003:137-48.

26 Bond CM, Matheson C. Drug misuse and community pharmacy in Scotland. In: Sheridan J, Strang J, eds. Drug misuse and community pharmacy. Taylor and Francis, 2003:47-62.

27 Matheson C, Bond CM, Mollison J. Attitudinal factors associated with community pharmacists' involvement in services for drug misusers. Addiction 1999;94:1349-59.

28 Matheson C, Bond CM, Pitcairn J. Community pharmacy services for drug misusers in Scotland: what difference does 5 years make? Addiction 2002;97:1405-11.

29 Matheson C, Bond CM, Tinelli M. Community pharmacy harm reduction services for drug misusers: national service delivery and professional attitude development over a decade in Scotland. J Public Health 2007;29:350-7.

30 Lovell S, Sheridan J, Harris J, Best D, Strang J. Methadone maintenance clients and the acceptability of supervised consumption of methadone. / Sub Use 1999;4:92-7.

31 Luger L, Bathia N, Alcorn R, Power R. Involvement of community pharmacies in the care of drug misusers: pharmacy-based supervision of methadone consumption. Int J Drug Policy 2000;11:227-34.

32 Roberts K. Supervised consumption of methadone in a community pharmacy. In: Tober G, Strang J, eds. Methadone matters: evolving community methadone treatment of opiate addiction. Martin Dunitz, 2003.

33 Berkshire four-way agreement scheme, 1999. Reported in Roberts K. Supervised consumption of methadone in a community pharmacy. In:Tober G, Strang J, eds. Methadone matters: evolving community methadone treatment of opiate addiction.Martin Dunitz, 2003. 
34 Cairns and Hender, 1999. Reported in Roberts K. Supervised consumption of methadone in a community pharmacy. In:Tober G, Strang J, eds. Methadone matters: evolving community methadone treatment of opiate addiction. Martin Dunitz, 2003.

35 Keen J. Managing drug misuse in general practice: new Department of Health guidelines provide a benchmark for good practice. BMJ 1999;318:1503-4.

36 Robertson JR. New British guidelines on the clinical management of drug misuse and drug dependence. Addiction 2000;95:325-6.

37 Strang J, Manning V, Mayet S, Ridge G, Best D, Sheridan J. Does prescribing for opiate addiction change after national guidelines? Methadone and buprenorphine prescribing to opiate addicts by general practitioners and hospital doctors in England, 1995-2005. Addiction 2007;102:761-70.

38 WHO Collaborating Centre for Drug Statistics Methodology. Guidelines for ATC classification and DDD assignment, 2010. WHO, 2009.

39 Department of Health (England) and the devolved administrations. Drug misuse and dependence: UK guidelines on clinical management. Department of Health, Scottish Government, Welsh Assembly Government, Northern Ireland Executive, 2007.
40 Degenhardt L, Day C, Dietz P, Pointer S, Conroy E, Collins L, et al. The effects of a sustained heroin shortage in three Australian states. Addiction 2005;100:908-20.

41 De Angelis D, Hickman M, Yang S. Estimating long-term trends in the incidence and prevalence of opiate use/injecting drug use and the number of former users: back calculation methods and opiate overdose deaths. Am J Epidemiol 2004;160:994-1004.

42 Hedrich D, Pirona A, Wiessing L. From margin to mainstream: the evolution of harm reduction responses to problem drug use in Europe. Drugs: Education, Prevention and Policy 2008;15:503-17.

43 Gossop M, Griffiths P, Powis B, Williamson S, Strang J. Frequency of non-fatal heroin overdose: survey of heroin users recruited in nonclinical settings. BMJ 1996;313:402.

44 Strang J, Griffiths P, Powis B, Gossop M. First use of heroin: changes in route of administration over time. BMJ 1992;304:1222-3.

45 Strang J, Griffiths P, Powis B, Gossop M. Heroin chasers and heroin injectors: differences observed in a community sample in London, UK. Am J Addict 1999;8:148-60.

46 Strang J, Sheridan J. Effect of government recommendations on methadone prescribing in south east England: comparison of 1995 and 1997 surveys. BMJ 1998;317:1489-90.

Accepted: 15 July 2010 